\title{
Perception of Threat and Psychological Impact of COVID-19 among Expatriates in Makkah Region, Saudi Arabia
}

\author{
Majed A. Algarni ${ }^{1, *(D)}$, Mohammad S. Alzahrani ${ }^{1}$, Yasser Alatawi ${ }^{2} \mathbb{D}$, Raghad A. Alasmari ${ }^{3}$, Hashem O. Alsaab ${ }^{4,5}$,
} Atiah H. Almalki ${ }^{5,6}$, Abdullah A. Alhifany ${ }^{7}$ and Yusuf S. Althobaiti ${ }^{3,5}{ }^{(D)}$

1 Department of Clinical Pharmacy, College of Pharmacy, Taif University, P.O. Box 11099, Taif 21944, Saudi Arabia; M.s.alzahrani@tu.edu.sa

2 Department of Pharmacy Practice, Faculty of Pharmacy, University of Tabuk, P.O. Box 741, Tabuk 71491, Saudi Arabia; Yasser@ut.edu.sa

3 Department of Pharmacology and Toxicology, College of Pharmacy, Taif University, P.O. Box 11099, Taif 21944, Saudi Arabia; s43602378@students.tu.edu.sa (R.A.A.); ys.althobaiti@tu.edu.sa (Y.S.A.)

4 Department of Pharmaceutics and Pharmaceutical Technology, Taif University, P.O. Box 11099, Taif 21944, Saudi Arabia; H.alsaab@tu.edu.sa

5 Addiction and Neuroscience Research Unit, Health Science Campus, Taif University, P.O. Box 11099, Taif 21944, Saudi Arabia; ahalmalki@tu.edu.sa

6 Department of Pharmaceutical Chemistry, College of Pharmacy, Taif University, P.O. Box 11099, Taif 21944, Saudi Arabia

7 Department of Clinical Pharmacy, College of Pharmacy, Umm Al-Qura University, Makkah 21955, Saudi Arabia; aahifany@uqu.edu.sa

Citation: Algarni, M.A.; Alzahrani, M.S.; Alatawi, Y.; Alasmari, R.A.; Alsaab, H.O.; Almalki, A.H.; Alhifany, A.A.; Althobaiti, Y.S. Perception of Threat and Psychological Impact of COVID-19 among Expatriates in Makkah Region, Saudi Arabia. Int. J. Environ. Res. Public Health 2021, 18, 6650. https://doi.org/10.3390/ ijerph18126650

Academic Editors: Ryuichi Ohta and Daisuke Son

Received: 6 May 2021

Accepted: 16 June 2021

Published: 21 June 2021

Publisher's Note: MDPI stays neutral with regard to jurisdictional claims in published maps and institutional affiliations.

Copyright: (c) 2021 by the authors. Licensee MDPI, Basel, Switzerland. This article is an open access article distributed under the terms and conditions of the Creative Commons Attribution (CC BY) license (https:// creativecommons.org/licenses/by/ $4.0 /)$.
* Correspondence: m.alqarni@tu.edu.sa; Tel.: +966-506-365-675

Abstract: In the first few months of the pandemic, Makkah region reported the highest number of COVID-19 cases among all regions in Saudi Arabia. More than $80 \%$ of these reported cases were non-Saudi residents. In this study, we evaluated the perceived threat from and psychological impact of COVID-19 among non-Saudi residents of Makkah region. This was a cross-sectional analysis of data collected using a standardized self-report questionnaire. A total of 292 expatriates were included in the study, the majority of whom were non-Arabic speakers. The prevalence of selfreported depression was nearly $40 \%$, anxiety was $32 \%$, and stress was $43 \%$. The findings indicated variability in the prevalence of psychological symptoms among expatriates from different ethnic backgrounds. Additionally, work environment and perceived threat were strong predictors of psychological disorders. This suggested that the perceived threat from and psychological burden of COVID-19 among non-Saudis in Makkah region is substantial. Future research should investigate the reasons behind these variations in the psychological impact of the pandemic among different ethnic groups.

Keywords: COVID-19; expatriates; psychological disorders; Saudi Arabia; DASS-21; BIP-Q5

\section{Introduction}

Coronavirus disease 2019 (COVID-19) is a severe respiratory disease that can lead to serious complications and death. The first case was reported in December 2019 as pneumonia of unknown origin in China [1]. In late January 2020, COVID-19 was declared a Public Health Emergency of International Concern by the World Health Organization [2]. A pandemic can affect communities and disrupt the norm, causing economic losses and depleting essential resources. There can also be an impact on individual health and well-being, leading to various emotional and psychological disorders. Psychological reactions during a pandemic play a significant role in creating outbreaks of both the disease and psychological disorders [3]. However, resources are usually not allocated to decrease the effects of a pandemic on individual mental health. Instead, mental health within communities is generally overlooked during the early stages of a pandemic, when managing the spread of infection is prioritized [3]. 
Over the past year, many studies have shown that the COVID-19 pandemic has negatively impacted people's mental health. High rates of psychological symptoms have been reported in China [4], India [5], Pakistan [6], Saudi Arabia [7], Egypt [8], the Philippines [9], and Bangladesh [10] for mental health disorders such as insomnia, depression, anxiety, and stress. For instance, a nationwide Chinese study of 52,730 participants reported that $35 \%$ experienced psychological distress following the pandemic [4], while a study in Saudi Arabia found that $23.6 \%$ of participants experienced moderate-to-severe psychological symptoms [7]. Moreover, the prevalence of psychological symptoms is expected to rise, owing to many variables [11]. It is plausible that these variables could affect people's mental health based on their sociodemographic status [12-14].

Evidence from previous public health emergencies indicates that socially disadvantaged groups (e.g., low-income groups, ethnic minorities) experience more health problems than socially advantaged groups [15]. Socially advantaged groups generally have access to more resources to cope with stressors caused by events such as pandemics and disasters. Thus, the disruption caused by the COVID-19 pandemic could disproportionately negatively affect the mental health of ethnic minorities and low-income individuals $[16,17]$. Notably, in Saudi Arabia, expatriates can be considered socially disadvantaged due to their low average income and lack of knowledge necessary to access appropriate resources to cope with the pandemic. However, there is little evidence of the impact of the COVID-19 pandemic on expatriates' mental health in Saudi Arabia. Thus, the main objective of this study is to evaluate the psychological impact and perception of threat during the pandemic among expatriates residing in Makkah region, Saudi Arabia. The other objective is to evaluate the differences in the pandemic's psychological impact between different expatriate ethnicities living in the Makkah region.

\section{Materials and Methods}

\subsection{Study Design and Participants}

This study utilized a cross-sectional survey design to assess the psychological impact of COVID-19 on the target population. We adopted convenience sampling to recruit expatriates living in Makkah region of Saudi Arabia during the COVID-19 pandemic from November 2020 to January 2021. The eligible study population included non-Saudi citizens aged 18 years or older who resided in Makkah region and spoke one of the following languages: Arabic, Urdu, Hindi, Bengali, or Filipino. We chose these languages because most non-Saudi residents working in Makkah region spoke at least one of them. The survey was distributed electronically, as this made it easier to circulate the questionnaire among expatriates. In addition, the Saudi government has encouraged people to minimize direct socializing as much as possible, which makes interviews and face-to-face surveys difficult. All participants provided electronic informed consent. The Scientific Research Ethics Committee of Taif University approved this study (42-0056).

\subsection{Sample Size Calculation}

We used Epi info ${ }^{\circledR}$ version 7 to calculate the study sample. The study sample was calculated to be 241 , assuming that $19.5 \%$ of the population would be psychologically distressed by COVID-19, based on a study conducted in of Saudi Arabia [18]. The confidence level was set at $95 \%$ and margin of error at $5 \%$.

\subsection{Measures}

The questionnaire contained 32 items: 11 demographic questions and 21 questions from the Depression, Anxiety, and Stress Scale-21 Items (DASS-21). We collected sociodemographic data including age, gender, educational level, marital status, living arrangements (living with family), whether one worked in the medical field, job satisfaction, and monthly income.

The DASS-21 was adapted to measure the psychological impact of COVID-19 [19]. This instrument is a 21-item self-report questionnaire comprising three subscales: depres- 
sion, anxiety, and stress. Each subscale contains seven items intended to measure the corresponding negative psychological state. Items are scored on a scale ranging from 0 (does not apply to me at all) to 3 (applies to me most of the time). Scores for each subscale are calculated by summing the scores for the relevant items and then multiplying this value by a factor of two. Using the recommended cut-off scores [12], each subscale was categorized into normal, mild/moderate, and severe/extremely severe. Further, each subscale was recoded into "yes" (above the cut-off score) or "no" (below the cut-off score) in relation to whether symptoms of the disorder were present in the participants.

The Brief Illness Perception Questionnaire (BIP-Q5) was also used to measure the threat participants perceived from the COVID-19 pandemic [20]. The BIP-Q5 comprises five items rated on a Likert-type scale ranging from 0 to 10 . Responses were calculated to provide a summary score for the threat perceived from the pandemic. The higher the summary score, the greater the perceived threat.

\subsection{Statistical Analysis}

Descriptive analysis of sociodemographic characteristics was conducted. Mean scores were calculated for the total DASS-21 and all three subscales. Frequencies and percentages were calculated for categorical variables. Three multiple logistic regression models were built to identify factors associated with each DASS-21 subscale (i.e., depression, anxiety, and stress). Two steps were performed to build each adjusted model. First, bivariate analysis was conducted using Pearson's chi-square test to evaluate the association between sociodemographic factors and each outcome. Second, factors that were significantly associated with the outcome $(p<0.05)$ were further analyzed and included in the adjusted model. Age and gender were included in the adjusted models, regardless of their bivariate association with the outcome. Odds ratios (ORs) and 95\% confidence intervals (CIs) were calculated. All statistical analyses were conducted using SAS version 9.4.

\section{Results}

In total, 292 participants completed the survey. Table 1 shows respondents' sociodemographic characteristics. Of the 292 respondents, 112 were non-Saudi Arabic language speakers (38\%), 55 were Bengali language speakers (19\%), 45 were Urdu language speakers $(15 \%), 43$ were Hindi language speakers (15\%), and 37 were Filipino language speakers $(13 \%)$. Additionally, $72 \%$ and $51 \%$ of the participants were men and between the ages of $18-34$ years, respectively. Approximately $47 \%$ of the participants had a monthly income between 266-1600 USD.

The mean scores for the DASS-21 subscales in each group are shown in Figure 1. The results indicated that there were significant differences in mean scores for depression $(\mathrm{F}(4,287)=11.76, p<0.0001)$, anxiety $(\mathrm{F}(4,287)=7.616, p<0.0001)$, and stress $(\mathrm{F}(4,287)=8.214, p<0.0001)$ among speakers of different languages. The post-hoc analysis found that Urdu speakers had significantly lower mean scores compared to Arabic speakers for all subscales $(p<0.05)$, while Hindi speakers had significantly higher mean scores compared to Arabic speakers for the depression and anxiety subscales $(p<0.0001$, $p=0.0280$ ). Figure 2 shows the prevalence and severity of each psychological disorder among the participants. The results showed that $39.39 \%, 43.84 \%$, and $32.53 \%$ of the participants reported symptoms of depression, anxiety, and stress, respectively. Notably, Hindi speakers were more likely to report severe symptoms of depression, anxiety, and stress compared to the other groups. For instance, $41.86 \%, 48.84 \%$, and $18.60 \%$ of Hindi speakers reported severe symptoms of depression, anxiety, and stress, respectively, while less than $7 \%$ of Urdu speakers reported severe symptoms for any of the DASS-21 subscales. 
Table 1. Sociodemographic characteristics of the respondents $(N=292)$.

\begin{tabular}{cc}
\hline Characteristic & $\mathbf{N}(\%)$ \\
Male & $211(72 \%)$ \\
Married & $161(56 \%)$ \\
Age & \\
$18-34$ years & $149(51 \%)$ \\
$35-44$ years & $83(28 \%)$ \\
$\geq 45$ years & $60(21 \%)$ \\
Education level & $129(45 \%)$ \\
Did not finish high school & $158(55 \%)$ \\
High school or higher & \\
Monthly income & $73(25 \%)$ \\
$<1000$ SR $\approx<266$ USD & $137(47 \%)$ \\
SR-6000 SR $\approx 266-1600$ USD & $80(28 \%)$ \\
$>6000$ SR $\approx 1600$ USD & $113(39 \%)$ \\
Living with family & $95(33 \%)$ \\
Working in the medical field & \\
Language & $112(38 \%)$ \\
Non-Saudi Arabic speakers & $55(19 \%)$ \\
Bengali speakers & $45(15 \%)$ \\
Urdu speakers & $43(15 \%)$ \\
Hindi speakers & $37(13 \%)$ \\
Filipino speakers & \\
Satisfied with work & $168(58 \%)$ \\
Yes & $124(42 \%)$ \\
No &
\end{tabular}

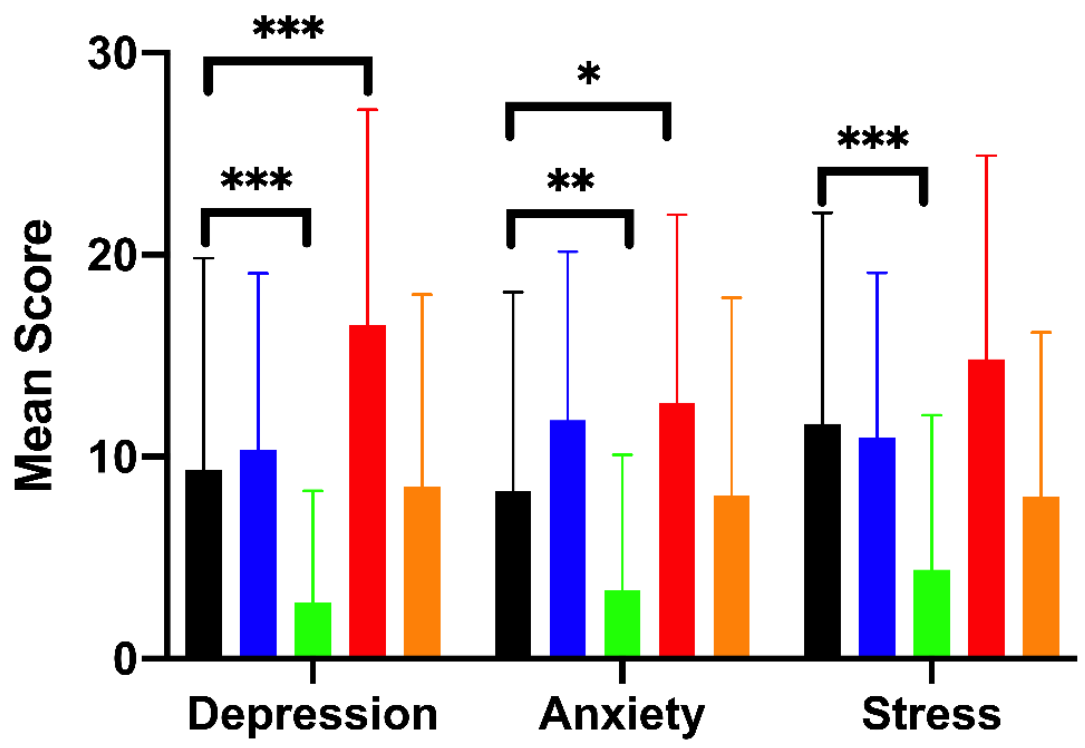

Arabic Speakers

Bengali Speakers

Urdu Speakersr

Hindi Speakers

Filipino Speakers

Figure 1. Average DASS-21 subscale scores by language speakers. ${ }^{*} p<0.05,{ }^{* *} p<0.01,{ }^{* * *} p<0.001$. 




Total $\mathbf{2} \mathbf{2 9 2}$
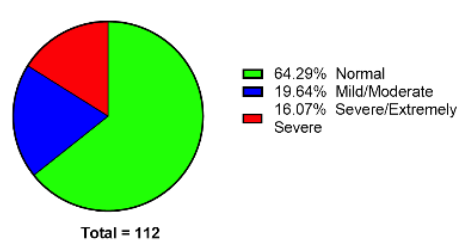

ש $\begin{aligned} & 16.07 \% \\ & \text { Severe }\end{aligned}$

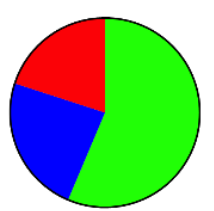

Total $=\mathbf{5 5}$

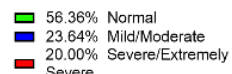

- $20.00 \%$ Sever

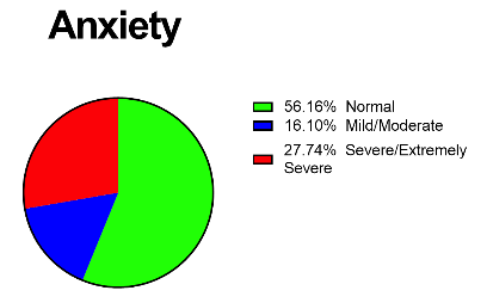

Total $=292$
Stress

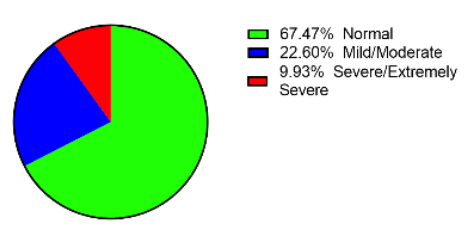

Total $=292$



므 $64.29 \%$ Normal

$23.21 \%$ Mild/Moderate
$12.50 \%$ Severe/Extremely 므 $13.39 \%$ Mild/Moderate - $25.89 \%$ Severe/Extremely

Total $=112$

Arabic Speakers

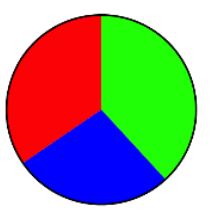

믐 $38.18 \%$ Normal
$27.27 \%$ Mild/Moderate
口 $34.55 \%$ Severe/Extremely
Severe

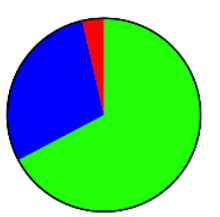

므 $67.27 \%$ Normal $29.69 \%$ Mild/Moderate - $3.64 \%$

\section{Bengali Speakers}

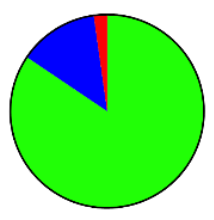

Total $=45$

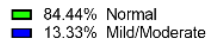

- $2.22 \%$ Severe/Extremely

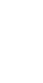
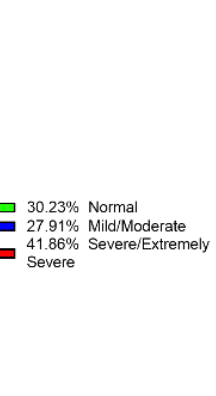

Total $=43$

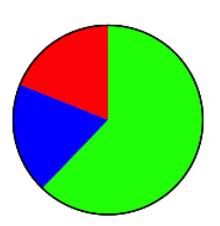

Total $=37$



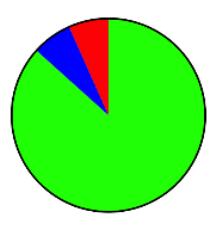

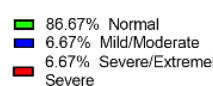

Total $=\mathbf{4 5}$

\section{Urdu Speakers}
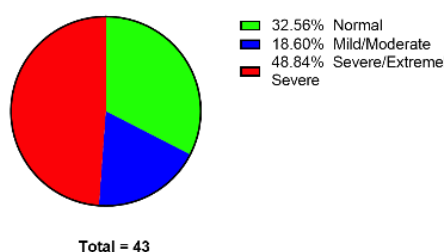

Hindi Speakers

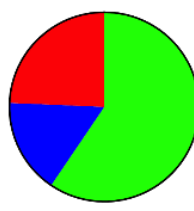

므 $59.46 \%$ Normal

- $24.32 \%$ Severe/Extremely

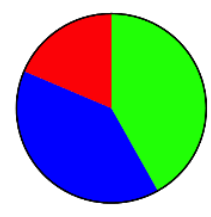

므 $41.86 \%$ Normal

$18.60 \%$ Severe/Extremely

口 Sever

ㅁ $95.35 \%$ Normal

- $2.33 \%$ Severe/Extremely

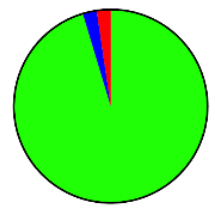

Total $=\mathbf{4 3}$

Total $=43$



므 $78.38 \%$ Normal

口 $5.41 \%$ Severe/Extremely

Total $=37$

Filipino Speakers

Figure 2. Prevalence and severity of psychological disorders by language spoken by participants. 
In comparison to male respondents, female respondents had a higher prevalence of anxiety $(54.32 \%$ vs. $39.81 \%, p=0.025)$ and depression $(49.3 \%$ vs. $35.5 \%, p=0.03$; Table 2$)$. Participants who lived with their families had a higher prevalence of stress than those who did not $(39.82 \%$ vs. $27.68 \%, p=0.03)$. Respondents who worked in the medical field had a significantly higher prevalence of anxiety $(58.95 \%$ vs. $37.31 \%, p=0.0005)$ and a higher prevalence of both depression ( $53.68 \%$ vs. $32.12 \%, p=0.0004)$ and stress $(43.16 \%$ vs. $27.98 \%$, $p=0.1$. Respondents who said that they were satisfied with their jobs during the pandemic had a significantly lower prevalence of anxiety compared to those who were not satisfied with their jobs ( $35.71 \%$ vs. $55.74 \%, p=0.0007)$, lower prevalence of depression $(29.76 \%$ vs. $53.28 \%, p \leq 0.0001)$, and lower prevalence of stress ( $26.2 \%$ vs. $41.8 \%, p=0.005)$. People in the lowest income category had a significantly higher prevalence of anxiety than those in the middle- and higher-income groups $(54.79 \%$ vs. $35 \%$ and $50 \%, p=0.01)$.

Table 2. Bivariate analysis of sociodemographic factors and psychological disorders.

\begin{tabular}{|c|c|c|c|c|c|c|}
\hline Characteristic & Anxiety \% & $p^{*}$ & Depression \% & $p^{*}$ & Stress \% & $p^{*}$ \\
\hline \multicolumn{7}{|l|}{ Gender } \\
\hline Male & 39.81 & \multirow{3}{*}{0.025} & 35.5 & \multirow{3}{*}{0.03} & 30 & \multirow{3}{*}{0.2} \\
\hline Female & 54.32 & & 49.3 & & 38 & \\
\hline Age & & & & & & \\
\hline $18-34$ & 42.28 & \multirow{3}{*}{0.006} & 38.9 & \multirow{3}{*}{0.2} & 32.89 & \multirow{3}{*}{0.03} \\
\hline $35-44$ & 56.63 & & 45.8 & & 40.96 & \\
\hline$\geq 45$ & 30 & & 31.7 & & 20 & \\
\hline \multicolumn{7}{|l|}{ Living with family } \\
\hline Yes & 47.79 & \multirow[b]{2}{*}{0.27} & 44.25 & \multirow[b]{2}{*}{0.17} & 39.82 & \multirow[b]{2}{*}{0.03} \\
\hline No & 41.24 & & 36.16 & & 27.68 & \\
\hline \multicolumn{7}{|c|}{ Working in the medical field } \\
\hline Yes & 58.95 & \multirow{2}{*}{0.001} & 53.68 & \multirow{2}{*}{$<0.001$} & 43.16 & \multirow{2}{*}{0.01} \\
\hline No & 37.31 & & 32.12 & & 27.98 & \\
\hline \multicolumn{7}{|l|}{ Monthly income } \\
\hline$<1000 \mathrm{SR}$ & 54.79 & \multirow{3}{*}{0.01} & 43.8 & \multirow{3}{*}{0.55} & 39.73 & \multirow{3}{*}{0.13} \\
\hline $1000-6000$ SR & 35 & & 36.5 & & 27 & \\
\hline$>6000 \mathrm{SR}$ & 50 & & 41.25 & & 36.25 & \\
\hline \multicolumn{7}{|l|}{ Satisfied with job } \\
\hline Yes & 35.71 & \multirow[b]{2}{*}{0.001} & 29.76 & \multirow[b]{2}{*}{$<0.001$} & 26.2 & \multirow[b]{2}{*}{0.005} \\
\hline No & 55.74 & & 53.28 & & 41.8 & \\
\hline \multicolumn{7}{|l|}{ Language } \\
\hline Arabic & 39.29 & \multirow{5}{*}{$<0.001$} & 35.71 & \multirow{5}{*}{$<0.001$} & 35.7 & \multirow{5}{*}{$<0.001$} \\
\hline Bengali & 61.82 & & 43.64 & & 32.7 & \\
\hline Urdu & 13.33 & & 15.56 & & 8.9 & \\
\hline Hindi & 67.44 & & 69.77 & & 58 & \\
\hline Filipino & 40.54 & & 37.84 & & 21.6 & \\
\hline
\end{tabular}

* $p$-values produced by Pearson's chi-square test.

The results showed that the perception of threat among participants on most of the BIP-Q5 items was significantly correlated with the DASS-21 subscales (Table 3). Specifically, a higher perception of threat regarding the consequences of the COVID-19 pandemic in one's life was positively correlated with higher scores for depression, anxiety, and stress $(r=0.29, p<0.0001 ; r=0.32, p<0.0001 ; r=0.31, p<0.0001$, respectively). As shown in Table 4, the multivariate analysis indicated that Hindi speakers were four to six times more likely to report symptoms of depression, anxiety, and stress (OR $=5.99,95 \% \mathrm{CI}$ : 2.53-14.17; OR = 5.23, 95\% CI: 2.09-13.08; OR = 4.37, 95\% CI: 1.80-10.70, respectively), while Filipino and Urdu speakers were less likely to report symptoms of stress ( $\mathrm{OR}=0.19$, 95\% CI: 0.05-0.86; OR $=0.22,95 \%$ CI: 0.06-0.85, respectively). Furthermore, perceived threat and job satisfaction were also significantly associated with all DASS-21 subscales. 
Table 3. Correlations between BIPQ-5 items and DASS-21 items.

\begin{tabular}{ccccccc}
\hline \multirow{2}{*}{ BIPQ-5 } & \multicolumn{9}{c}{ DASS-21 } \\
\cline { 2 - 7 } & \multicolumn{2}{c}{ Depression } & \multicolumn{2}{c}{ Anxiety } & \multicolumn{2}{c}{ Stress } \\
\cline { 2 - 7 } & $\boldsymbol{r}$ & $\boldsymbol{p}$ & $\boldsymbol{r}$ & $\boldsymbol{p}$ & $\boldsymbol{r}$ & $\boldsymbol{p}$ \\
\hline Consequences & 0.29 & $<0.001$ & 0.32 & $<0.001$ & 0.31 & $<0.001$ \\
Timeline & 0.27 & $<0.001$ & 0.35 & $<0.001$ & 0.31 & $<0.001$ \\
Identity & 0.12 & 0.034 & 0.19 & 0.001 & 0.09 & 0.090 \\
Concern & 0.09 & 0.104 & 0.18 & 0.003 & 0.10 & 0.077 \\
Emotional response & 0.24 & $<0.001$ & 0.33 & $<0.001$ & 0.19 & 0.001 \\
Summary score & 0.27 & $<0.001$ & 0.36 & $<0.001$ & 0.27 & $<0.001$ \\
\hline
\end{tabular}

Abbreviations: BIPQ-5: 5-item brief illness perception questionnaire; DASS-21: Depression Anxiety Stress Scale; $r$ Pearson correlation coefficient.

Table 4. Multivariate logistic analysis results for depression, anxiety, and stress.

\begin{tabular}{cccc}
\hline Predictors & Adjusted OR & $\mathbf{9 5 \%}$ CI & $p$ \\
\hline Factors associated with anxiety & & & \\
Filipino speakers (vs. Arabic speakers) & 0.28 & $0.08-0.88$ & 0.006 \\
Hindi speakers (vs. Arabic speakers) & 5.23 & $2.09-13.08$ & $<0.001$ \\
35-44 years old (vs. >45 years old) & 2.92 & $1.23-6.89$ & 0.018 \\
Income 1000-6000 SR (vs. <1000 SR) & 0.43 & $0.21-0.89$ & 0.004 \\
Satisfied with job (yes vs. no) & 0.39 & $0.21-0.72$ & 0.003 \\
Perceived threat from COVID-19 & 1.07 & $1.04-1.10$ & $<0.001$ \\
Factors associated with depression & & & \\
Hindi speakers (vs. Arabic speakers & 5.99 & $2.53-14.17$ & $<0.001$ \\
Satisfied with job (yes vs. no) & 0.37 & $0.21-0.66$ & 0.001 \\
Perceived threat from COVID-19 & 1.05 & $1.03-1.08$ & $<0.001$ \\
Factors associated with stress & & & \\
Living with family (yes vs. no) & 2.53 & $1.23-5.27$ & 0.012 \\
Hindi speakers (vs. Arabic speakers & 4.37 & $1.8-10.7$ & $<0.001$ \\
Filipino speakers (vs. Arabic speakers) & 0.19 & $0.05-0.68$ & 0.005 \\
Urdu speakers (vs. Arabic speakers) & 0.22 & $0.06-0.85$ & 0.021 \\
Working in medical field (yes vs. no) & 2.02 & $1.03-3.98$ & 0.041 \\
Perceived threat from COVID-19 & 1.04 & $1.02-1.07$ & 0.001 \\
\hline
\end{tabular}

\section{Discussion}

This study found a high prevalence of psychological symptoms among expatriates in Saudi Arabia during the COVID-19 pandemic. This highlights the significant impact of the pandemic on people's mental health, especially among expatriates. Over a third of the participants reported symptoms of depression, anxiety, and stress. This was in line with some previous research, such as one study that examined the prevalence of stress among expatriates in the Al-Ahsa region and found that 31\% reported severe symptoms of stress during the travel ban [21]. Another recent study found that $19.7 \%$ of expatriates reported symptoms of depression [22].

Additionally, the present study found that there are variations in the prevalence of psychological symptoms among speakers of different languages. For instance, Indian expatriates showed a higher chance of experiencing anxiety, depression, and stress than non-Saudi Arabic speakers. Although it is not clear why Indians have a higher chance of becoming anxious and depressed, one explanation could be the language barrier. However, speakers of other languages showed lower odds compared to non-Saudi Arabic speakers. A study conducted in Bahrain, a GCC country, found that Pakistanis had higher rates of stress, anxiety, and depression than Indians; however, Indians were overrepresented in the sample [23]. Another study conducted on Indian expatriates in the Middle East found that psychological stress in this population was significantly higher compared to the pre-COVID-19 period [24]. A recent study conducted in Saudi Arabia that examined stress due to travel bans among expatriates found that those from India experienced the 
highest levels of stress [21]. A study conducted with male expatriates in Saudi Arabia found that Indian people experienced more depressive symptoms than Pakistanis and Egyptians [22]. The differences among ethnic groups found in the present study may be due to different sociocultural factors or actual differences in the psychological burden on different ethnic groups residing in Saudi Arabia. This highlights two important points. First, it is necessary to give further attention to the mental health of expatriates, even after the COVID-19 pandemic, to understand the root of this issue. Second, stronger policy decisions are needed that aim to provide expatriates with access to appropriate mental health care.

In a study that was published last year and was conducted on the general Saudi population, [7] the authors found that $70 \%$ of the sample was in the normal range of the stress and anxiety subscales, and $60 \%$ was in the normal range of the depression subscale. We can see that there is a clear difference between these findings and the findings of this study, which may imply that expatriates in Saudi Arabia have suffered psychologically more than Saudi citizens.

This study also found that working in the medical field, which included approximately one-third of the 292 respondents (33\%), was associated with depression and stress. In line with this finding, a cross-sectional study of healthcare workers in Saudi Arabia and Egypt reported high prevalence rates for depression (69\%), anxiety (59\%), and stress (56\%) during the COVID-19 pandemic [25]. In contrast, the prevalence rates for depression, anxiety, and stress were shown to be very low among healthcare workers in Singapore $(8 \%, 11 \%$, and $6 \%$, respectively) [26]. These relatively low rates of psychological symptoms compared to many countries in the Middle East could be attributed to the high preparedness and rigorous infection control measures in Singapore that were enacted following the SARS epidemic. Furthermore, the results also suggested that work satisfaction is associated with lower levels of psychological symptoms. Similarly, one study in Saudi Arabia found that job dissatisfaction among nurses was associated with mild-to-moderate depression [27].

This study found that perceived threat from the COVID-19 pandemic was associated with an increased risk for depression, anxiety, and stress. These findings are consistent with previous evidence which indicated that a perceived threat increases the risk of stress and may subsequently lead to the development of psychological disorders $[28,29]$. For instance, a study in Spain found that the perception of threat was associated with anxiety and depression [30].

This study has some limitations. First, the use of convenience sampling and the small sample size might limit the generalizability of the results. Further investigation is required to include a more diverse sample that represents the expatriate population in Saudi Arabia. Second, we did not have sufficient resources to validate these instruments in different languages. However, these instruments have been validated and translated into many languages, including those used in this study [31].

\section{Conclusions}

Almost half the population of Makkah region is composed of non-Saudi residents. In this study, we explored perceived threat from and the psychological impact of the COVID-19 pandemic among expatriates residing in Saudi Arabia. The findings indicated a high prevalence of depression, anxiety, and stress among expatriates. Moreover, it was found that there is variability in the prevalence of psychological symptoms among expatriates from different ethnic backgrounds. Additionally, work environment and perceived threat were strong predictors of psychological symptoms. Further research is needed to better understand differences in psychological symptoms among expatriates working in Saudi Arabia. 
Author Contributions: Conceptualization, M.A.A. and Y.S.A.; methodology, M.S.A. and Y.A.; validation, H.O.A., A.H.A. and A.A.A.; formal analysis, M.A.A., M.S.A. and Y.A.; data curation, R.A.A.; writing-original draft preparation, M.A.A., M.S.A. and Y.S.A.; writing-review and editing, Y.A., H.O.A., A.A.A.; visualization, A.H.A.; supervision, M.A.A. and Y.S.A. All authors have read and agreed to the published version of the manuscript.

Funding: This research was funded by Taif University initiative for COVID-19 projects, grant number 1-441-74.

Institutional Review Board Statement: Experiments were approved by the Research Ethics Committee at Taif University 42-0056.

Informed Consent Statement: Informed consent was obtained from all subjects involved in the study.

Data Availability Statement: Data are available upon reasonable request to the corresponding author.

Acknowledgments: Authors thank Bashaier G. AlQahtani for her initial help in the study.

Conflicts of Interest: The authors declare no conflict of interest.

\section{References}

1. Wang, C.; Horby, W.P.; Haiden, F.G.; Gao, G.F. A novel coronavirus outbreak of global health concern. Lancet 2020, 395, 470-473. [CrossRef]

2. Cucinotta, D.; Vanelli, M. WHO declares COVID-19 a pandemic. Acta Bio Medica Atenei Parm. 2020, 91, 157.

3. Cullen, W.; Gulati, G.; Kelly, B.D. Mental health in the COVID-19 pandemic. QJM Int. J. Med. 2020, 113, 311-312. [CrossRef]

4. Qiu, J.; Shen, B.; Zhao, M.; Wang, Z.; Xie, B.; Xu, Y. A nationwide survey of psychological distress among Chinese people in the COVID-19 epidemic: Implications and policy recommendations. Gen. Psychiatry 2020, 33, e100213. [CrossRef]

5. Grover, S.; Sahoo, S.; Mehra, A.; Avasthi, A.; Tripathi, A.; Subramanyam, A.; Pattojoshi, A.; Rao, G.P.; Saha, G.; Mishra, K.K.; et al. Psychological impact of COVID-19 lockdown: An online survey from India. Indian J. Psychiatry 2020, 62, 354-362. [CrossRef]

6. Hayat, K.; Haq, M.; Wang, W.; Khan, F.; Rehman, A.; Rasool, M.; Kadirhaz, M.; Omer, S.; Rasheed, U.; Fang, Y. Impact of the COVID-19 outbreak on mental health status and associated factors among general population: A cross-sectional study from Pakistan. Psychol. Health Med. 2021. [CrossRef]

7. Alkhamees, A.A.; Alrashed, S.A.; Alzunaydi, A.A.; Almohimeed, A.S.; Aljohani, M.S. The psychological impact of COVID-19 pandemic on the general population of Saudi Arabia. Compr. Psychiatry 2020, 102, 152192. [CrossRef]

8. Arafa, A.; Mohamed, A.; Saleh, L.; Senosy, S. Psychological Impacts of the COVID-19 Pandemic on the Public in Egypt. Community Ment. Health J. 2021, 57, 64-69. [CrossRef]

9. Montano, R.L.T.; Acebes, K.M.L. Covid stress predicts depression, anxiety and stress symptoms of Filipino respondents. International J. Res. Bus. Soc. Sci. 2020, 9, 78-103. [CrossRef]

10. Islam, S.M.D.-U.; Doza, M.; Khan, R.; Haque, A.; Mamun, M. Exploring COVID-19 stress and its factors in Bangladesh: A perception-based study. Heliyon 2020, 6, e04399. [CrossRef]

11. Wheaton, M.G.; Abramowitz, J.S.; Berman, N.C.; Fabricant, L.E.; Olatunji, B.O. Psychological predictors of anxiety in response to the H1N1 (swine flu) pandemic. Cogn. Ther. Res. 2012, 36, 210-218. [CrossRef]

12. Fornili, M.; Petri, D.; Berrocal, C.; Fiorentione, G.; Ricceri, F.; Macciotta, A.; Bruno, A.; Farinella, D.; Baccini, M.; Severi, G.; et al. Psychological distress in the academic population and its association with socio-demographic and lifestyle characteristics during COVID-19 pandemic lockdown: Results from a large multicenter Italian study. PLoS ONE 2021, 16, e0248370. [CrossRef] [PubMed]

13. Solomou, I.; Constantinidou, F. Prevalence and predictors of anxiety and depression symptoms during the COVID-19 pandemic and compliance with precautionary measures: Age and sex matter. Int. J. Environ. Res. Public Health 2020, 17, 4924. [CrossRef]

14. Holingue, C.; Badillo, E.; Riehm, K.E.; Veldhuis, C.B.; Thrul, J.; Johson, R.M.; Fallin, D.M.; Kreuter, F.; Stuart, E.A.; Kalb, L.G. Mental distress during the COVID-19 pandemic among US adults without a pre-existing mental health condition: Findings from American trend panel survey. Prev. Med. 2020, 139, 106231. [CrossRef] [PubMed]

15. Purtle, J. Racial and ethnic disparities in post-disaster mental health: Examining the evidence through a lens of social justice. Wash. Lee J. Civil. Rts. Soc. Just. 2012, 19, 31.

16. Warren, M.A.; Bordoloi, S. When COVID-19 exacerbates inequities: The path forward for generating wellbeing. Int. J. Wellbeing 2020, 10, 1-6. [CrossRef]

17. Kola, L.; Kohrt, B.A.; Hanlon, C.; Naslund, J.A.; Sikander, S.; Balaji, M.; Benjet, C.; Cheung, E.Y.L.; Eaton, J.; Gonsalves, P.; et al. COVID-19 mental health impact and responses in low-income and middle-income countries: Reimagining global mental health. Lancet Psychiatry 2021, 8, 535-550. [CrossRef]

18. Alatawi, Y.; Alshehri, F.S.; Alhifany, A.A.; Alharbi, A.; Alghamdi, B.S. Health Literacy, Perceived Threat, and Posttraumatic Stress Disorder During the COVID-19 Pandemic in Saudi Arabia. Risk Manag Healthc Policy 2020, 13, 3147-3153. [CrossRef] [PubMed]

19. Antony, M.M.; Bieling, P.J.; Cox, B.J.; Enns, M.W.; Swinson, R.P. Psychometric properties of the 42-item and 21-item versions of the Depression Anxiety Stress Scales in clinical groups and a community sample. Psychol. Assess. 1998, 10, 176. [CrossRef] 
20. Broadbent, E.; Petrie, K.J.; Main, J.; Weinman, J. The brief illness perception questionnaire. J. Psychosom. Res. 2006, 60, 631-637. [CrossRef]

21. Jalal, S.M.; Chacko, S.K.; David, M.S.; Khamseen, Z.M.B. Stress due to Travel Ban for Pandemic during Vacation among Expatriates of Saudi Arabia. Int. J. Nurs. Care 2021, 9, 26-35. [CrossRef]

22. Ukuhor, H.O. Prevalence and sociodemographic correlates of depressive symptoms among male expatriate workers in Saudi Arabia. Majmaah. J. Health Sci. 2020, 8, 61-77. [CrossRef]

23. Prevalence of stress, anxiety and depression among expatriate workers. Virtual Health Sciences Library. Available online: https:/ / vlibrary.emro.who.int/imemr/prevalence-of-stress-anxiety-and-depression-among-expatriate-workers-2/ (accessed on 21 April 2021).

24. Uvais, N.A.; Nalakath, M.J.; Shihabudheen, P.; Hafi, N.A.B.; Rasmina, V.; Salman, C.A. Psychological distress during COVID-19 among Malayalam-speaking Indian expats in the middle east. Indian J. Public Health. 2020, 64, S249-S250. [CrossRef] [PubMed]

25. Arafa, A.; Mohammed, Z.; Mahmoud, O.; Elshazley, M.; Ewis, A. Depressed, anxious, and stressed: What have healthcare workers on the frontlines in Egypt and Saudi Arabia experienced during the COVID-19 pandemic? J. Affect. Disord. 2021, 278, 365-371. [CrossRef] [PubMed]

26. Tan, B.Y.Q.; Chew, N.W.S.; Lee, G.K.H.; Jing, M. Psychological Impact of the COVID-19 Pandemic on Health Care Workers in Singapore. Ann. Intern. Med. 2020. [CrossRef] [PubMed]

27. Saquib, N.; Zaghloul, M.S.; Saquib, J.; Alhomaidan, H.T.; Al-Mohaimeed, A.; Al-Mazrou, A. Association of cumulative job dissatisfaction with depression, anxiety and stress among expatriate nurses in Saudi Arabia. J. Nurs. Manag. 2019, 27, 740-748. [CrossRef]

28. Bauer, E.A.; Braitman, A.L.; Judah, M.R.; Cigularov, K.P. Worry as a mediator between psychosocial stressors and emotional sequelae: Moderation by contrast avoidance. J. Affect. Disord. 2020, 266, 456-464. [CrossRef]

29. Jin, Y.; Austin, L.; Vijaykumar, S.; Jun, H.; Nowak, G. Communicating about infectious disease threats: Insights from public health information officers. Public Relat. Rev. 2019, 45, 167-177. [CrossRef]

30. Del Pérez-Fuentes, M.C.; del Molero, J.M.M.; Martos, M.Á.; Gázquez, L.J.J. Threat of COVID-19 and emotional state during quarantine: Positive and negative affect as mediators in a cross-sectional study of the Spanish population. PLoS ONE 2020, 15. [CrossRef]

31. Bibi, A.; Lin, M.; Zhang, X.C.; Margraf, J. Psychometric properties and measurement invariance of Depression, Anxiety and Stress Scales (DASS-21) across cultures. Int. J. Psychol. 2020, 55, 916-925. [CrossRef] 